\title{
Algerian Arabic rhythm classification
}

\author{
Ghania Droua-Hamdani ${ }^{1}$, Sid Ahmed Selouani ${ }^{2}$, Malika Boudraa ${ }^{3}$, \\ Wladyslaw Cichocki ${ }^{2}$ \\ ${ }^{1}$ SPS Laboratory CRSTDLA, Algiers, Algeria \\ ${ }^{2}$ LARIHS Lab. Moncton University, Canada \\ ${ }^{3}$ LCPS. USTHB. Algiers, Algeria \\ https://doi.org/10.36505/ExLing-2010/03/0010/000130
}

\begin{abstract}
This paper investigates speech timing in Modern Standard Arabic (MSA) of Algerian speakers in order to situate their Arabic language between stressed-timed and syllable-timed languages. We extracted first all duration measurements from recordings taken from sound voice bank ALGASD (ALGerian Arabic Speech Database) and after computed durations with using recently interesting rhythmic approaches.
\end{abstract}

Key words: duration, rhythm, Algerian speakers, Arabic language.

\section{Introduction}

Human speech rhythm was principally classified into three big categories: syllable-timed, stress-timed or mora-timed Pike (1945), Abercrombie (1967), Blosh, B. (1950), Ladforged (1975). Nowadays, different experimental studies investigate in rhythmic differences between or within languages in order to modelling them with evidences and metrics which will disclose between their prosodic characteristics Ramus (2002), Grabe (2003), Dellwo (2004), Barry (2003), White (2007).

In the rhythm class typology, Modern Standard Arabic (MSA) language has been described as belonging to stressed-timing family Abercrombie (1967). Practical rhythm studies related to MSA are relatively less numerous comparing to the large number of works dealing with other languages as: English, Dutch, Korean, French, Spanish, Portuguese, and Greek. Ramus (2002), Grabe (2003), Jang (2009), Baltazani (2007), O'Rourk (2008).

The purpose of this paper is to investigate speech rhythm of 73 Algerian speakers in order to situate Algerian MSA between languages. Traditionally Arabic is considered to be a stressed-timing language but what about the location of Algerian Arabic between languages in general and between stressed ones in particular?

\section{Methodology}

Sound material, taken from ALGASD (ALGerian Arabic Speech Database) voice bank, is composed of two sentences read by all speakers Droua-Hamdani (2010). Analysis consists on extraction ancomputing all

ExLing 2010: Proceedings of 3rd Tutorial and Research Workshop on Experimental Linguistics, 25-27 August, Athens, Greece 
vowels and consonants duration measurements by using recently interesting rhythmic approaches which are Ramus and Grabe methods which are:

\section{Interval measures (IM)}

Ramus approach suggested computing three separate variables which are taken to be acoustic correlates of rhythm classes. These evidences or interval measures (IM) are providing from speech signal segmentation into vocalic and consonantal units. IM correlates are: $\% \mathrm{~V}$ the proportion of total utterance duration which comprises vocalic intervals; $\Delta \mathrm{V}$ the standard deviation of vocalic intervals and $\Delta \mathrm{C}$, the standard deviation of consonantal intervals.

\section{Pairewise variability indices (PVI)}

PVI variables are quantitative measures which express the level of variability in successive measurements. nPVI-V parameter calculates the normalized differences of subsequent vocalic durations and rPVI-C one computes successive intervocalic differences intervals (consonants). Their respective formulas are:

$$
n P V I=100 \times \frac{\left(\sum_{k=1}^{m-1}\left|\frac{\left(d_{k}-d_{k+1}\right)}{\left(d_{k}+d_{k+1}\right) / 2}\right|\right)}{(m-1)} \quad r P V I=\frac{\left(\sum_{k=1}^{m-1}\left|d_{k}-d_{k+1}\right|\right)}{(m-1)}
$$

\section{Experimentation \& results}

Traditionally, stressed languages such as English and Dutch are characterized by their highest $\Delta \mathrm{C}$ and the lowest $\% \mathrm{~V}$ or by high vocalic nPVI and rPVI. However by applying different interval measures of rhythm calculation on Algerian MSA, we founded that Algerian language presents simultaneously a rising $\Delta \mathrm{C}$ and $\% \mathrm{~V}$. By comparing results with previous findings reported in different studies made for: stress-timed languages (English, Dutch, German, etc.); syllable-timed languages (French; Italian, Spanish, etc.); mora-timed ones (Japanese) and mixed languages (Polish and Catalan), we noticed from the projection on $(\Delta \mathrm{C}, \% \mathrm{~V})$ plane, that the location of Algerian MSA belongs to stress-timed family of languages but set back a bit from them to pattern with syllable-timed languages as French one concerning the $\% \mathrm{~V}$ values.

As regards to Grabe's variables, Algerian rPVI-C is raising as stressed language, but its nPVI-V score seems to be similar that for syllable-timed French and appears on (nPVI-V, rPVI-C) representation patterning Catalan language which is classified as a mixed language. 
Figure 1 and Figure 2 show the location of Algerian speakers among languages (stressed, timed, mora and mixed) studied by Ramus and Grabe using respectively IM and PVI correlates.

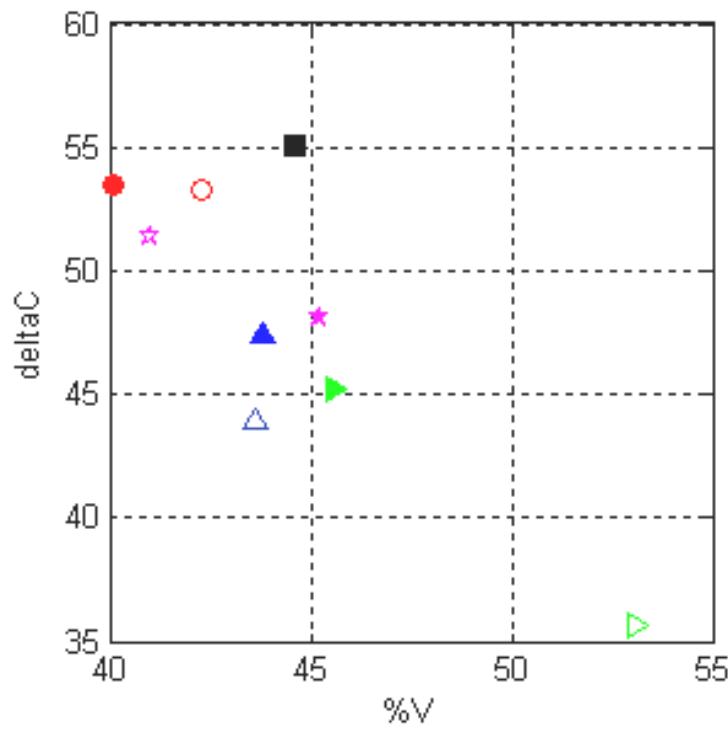

\begin{tabular}{|ll|}
\hline $\mathbf{u}$ & MSA \\
$\mathbf{O}$ & English \\
$\mathbf{\Delta}$ & Setherlands \\
$\Delta$ & French \\
$\star$ & Italian \\
$\Delta$ & Polish \\
& Catalan \\
& Japanese \\
\hline
\end{tabular}

Figure 1. Algerian MSA location between languages according to Ramus measures.
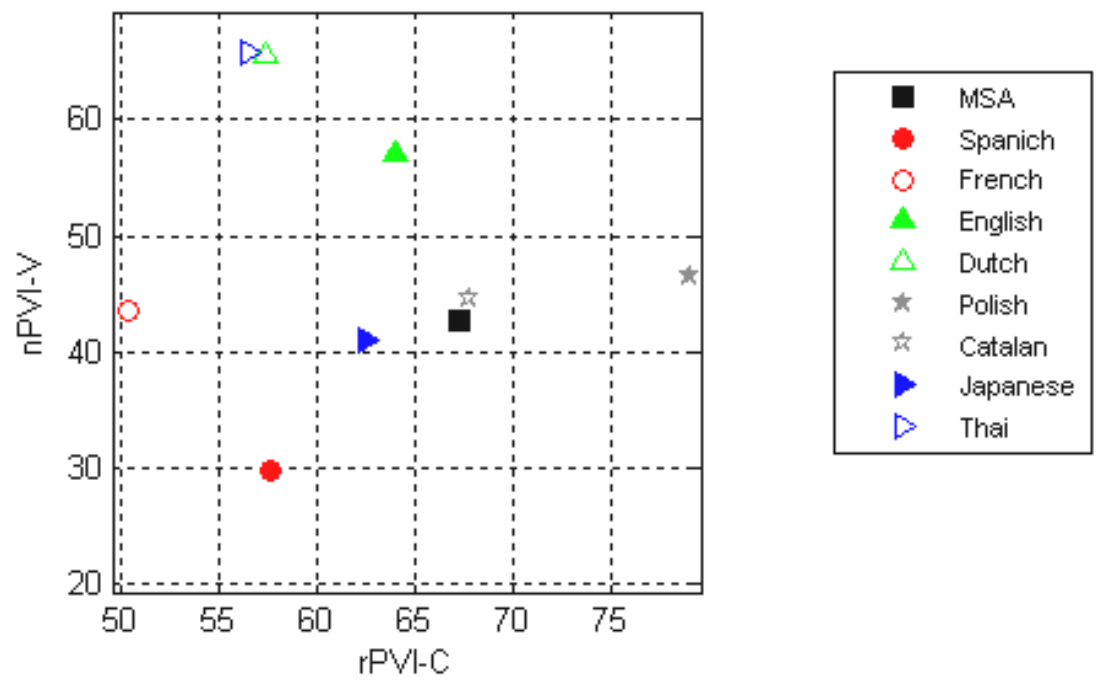

Figure 2. Algerian MSA location between languages according to Grabe measures. 
From results, we conclude that although Arabic is classified as stressed language, Algerians tend to pronounce the MSA as an intermediate language (mixed) between stressed and timed languages.

\section{References}

Baltazani, M. 2007. Prosodic rhythm and the status of vowel reduction in Greek. In Selected Papers on Theoretical and Applied Linguistics from the 17th International Symposium on Theoretical \& Applied Linguistics, Volume 1, pp. 3143. Department of Theoretical and Applied Linguistics, Salonica.

Barry, W.J., Andreeva, B., Russo, M., Dimitrova, S., Kostadinov, T. 2003. Do rhythm measures tell us anything about language type? Proc. of the 15th $\mathrm{ICPhS}$, Barcelona, Spain.

Blosh, B. 1950. Studies in colloquial Japanese IV: Phonemics. Language 26, 86-125.

Jang, T-Y. 2009. Automatic assessment of non-native prosody using rhythm metrics: Focusing on Korean speakers' English pronunciation. In SFU Working Papers in Linguistics Vol. 2 . Simon Fraser University, Vancouver, Canada.

Ladefoged, P. 1975. A Course in Phonetics. New York: Harcourt Brace Jovanovich.

Ramus, F. 2002. Acoustic correlates of linguistic rhythm: Perspectives. In Proc. of speech prosody, 115-120. Aix-en-Provence, France

Abercrombie, D. 1967. Elements of general phonetics. Chicago: Aldine.

Dellwo, V. 2004. Rhythm and speech rate: A variation coefficient for DC. In Karnowski, P. and Szigeti, (ed). Language and language-processing 231-241. Frankfurt am Main: Peter Lang.

Droua-Hamdani, G., Selouani, S.A., Boudraa M. 2010. Algerian Arabic Speech Database (ALGASD): Description and research applications. In Proc. conference language resources and human language technologies for Semitic languages. Valetta, Malta.

Grabe, E., Low, E.L. 2003. Durational variability in speech and the rhythm class hypothesis. Papers in laboratory phonology 7, 515-546.

O'Rourk, E. 2008: Speech rhythm variation in dialects of Spanish: Applying the Pairewise Variability Index and variation Coefficients to Peruvian Spanish. Speech Prosody, 6-9 May, Brazil.

Pike, K.L. 1945. The intonation of American English. The University of Michigan Press.

White, L., Mattys, S. 2007. Calibrating rhythm: First language and second language studies. Journal of Phonetics 35, 501-522. 